\title{
Lewis Morgan: 140 anos dos Sistemas de Consanguinidade e Afinidade da Família Humana (1871-2011)
}

\author{
Mauro William Barbosa de Almeida
}

resumo Lewis Henry Morgan costuma ser agrupado com McLennan, Lubbock e Tylor como um dos evolucionistas de gabinete cuja obra é mencionada no início de cursos de antropologia, mas cuja leitura não é recomendada. Na verdade, Morgan foi um pioneiro da pesquisa de campo, cujo primeiro projeto teórico foi provar a unidade humana e a origem asiática dos povos ameríndios, utilizando para isso um método que pode legitimamente ser chamado de estrutural. O evolucionismo de Morgan, ou o que ele chamou de "explicação conjetural" da diversidade de terminologias de parentesco por meio de uma sequência progressiva de formas de família, foi um adendo à sua monumental obra Sistemas de Consanguinidade e de Afinidade na Família Humana, publicada em 1871. A "explicação conjetural" é o foco central de sua obra mais conhecida que é $A$ Sociedade Antiga, publicada em 1877. Mas, ainda que esta segunda obra não tivesse sido publicada, Morgan mereceria o reconhecimento de ter sido o criador do objeto "sistema de parentesco", de ter criado um método para estudá-lo, e de ter realizado um esforço de pesquisa comparativa sem igual até os dias de hoje. Lewis Morgan foi ainda um pioneiro na pesquisa de sistemas políticos, da arquitetura e da comensalidade de indígenas ameríndios, além de ter sido um naturalista que defendeu os seres "mudos", a quem atribuiu inteligência igual em sua natureza à dos seres dotados de fala.

palavras-chave Morgan. Antropologia. Parentesco. Evolucionismo. História Humana.
Segundo Thomas Trautmann, alguns aspectos básicos do saber antropológico foram profundamente moldados por Morgan, quer tenhamos noção disso ou não. Em outras palavras, Morgan foi incorporado ao inconsciente coletivo do pensamento antropológico (Trautmann, 2008, p. v). A disciplina da Antropologia, ainda conforme Trautmann, não surgiu em consequência da expansão europeia no espaço do colonialismo, como reza o ensino habitual. Ela seria, antes, o resultado de uma hiperinflação nos quadros temporais da história humana, em cuja esteira criou-se um enorme vácuo a ser preenchido por narrativas conjeturais. No centro dessa nova narrativa estava o parentesco. Há consenso pelo menos sobre o seguinte:

o parentesco como objeto de estudo foi virtualmente inventado por Morgan, e em grande medida a antropologia cristalizou-se em torno do parentesco e dos problemas intelectuais gerados por ele (Op. cit., p. vi).

Lewis Henry Morgan (1818-1881) cresceu em uma cidade no estado de New York, habitada outrora por povos indígenas que incluíam os Iroqueses. Depois de formar-se em 1840, tornou-se advogado. Em 1844, mudou-se para Rochester, onde residiu pelo resto da vida. A partir de 1842 estudou os iroqueses e, em 1851, publicou o livro intitulado Liga dos Iroqueses, até hoje reputado como uma importante

cadernos de campo, São Paulo, n. 19, p. 1-384, 2010 
monografia sobre a organização política indígena. Em 1856, voltou à pesquisa etnográfica, da qual resultou uma publicação sobre as "leis de descendência dos Iroqueses" (1857) em que manifestava o interesse pelas relaçóes entre as estranhas regras iroquesas, que contavam a descendência pela linha feminina e náo distinguiam os descendentes diretos dos colaterais, e as dos demais índios norte-americanos. $\mathrm{O}$ trabalho que resultou nos seus Systems of Consanguinity and Affinity in the Human Family iniciou-se, porém, no verão de 1858 , com a descoberta de que os Ojibwa, embora fossem patrilineares, ignoravam a distinção entre descendentes diretos e descendentes colaterais, tratando de "filho" tanto o filho propriamente dito como o filho do irmáo. No verão de 1858 , após pedir dados sobre o assunto a um missionário que retornava da Índia do Sul, Morgan descobriu que a terminologia de parentesco Tamil exibia o mesmo padrão de fusão dos descendentes diretos e colaterais exibido pelos Ojibwa e pelos Iroqueses. Esse foi o grande marco intelectual na trajetória que levou à redação dos Systems. Nas palavras do próprio Morgan:

Minha surpresa foi maior do que consigo expressar ao descobrir que o sistema Tamil e o sistema dos índios norte-americanos eram substancialmente idênticos (Morgan apud Trautmann, 2008, p. 15).

Essa descoberta confirmava para Morgan a hipótese da origem asiática dos povos indígenas americanos, mas também embutia a descoberta de um novo método de investigação: a comparação de "sistemas de consanguinidade e afinidade". A partir daí, Morgan elaborou um questionário detalhado sobre termos de parentesco, que foi distribuído a missionários e representantes diplomáticos através do mundo, com ajuda do governo norte-americano. O texto, datado de 1858, era acompanhado de um artigo de 13 páginas em que Morgan anunciava as teses da primeira versão da obra, entregue para publicaçáo em 1865 , já com o título Systems of Consanguinity and Affinity in the Human Family. A pesquisa e a redação dessa primeira versão dos Systems durou, pois, de 1859 a 1865, sendo que a coleta de terminologias de parentesco de índios norte-americanos foi realizada principalmente pelo próprio Morgan de 1859 a 1862 (Trautmann, 2008; Resek, 1960; White, 1951).

A obra terminada em 1865 seria suficiente para assegurar a Morgan um lugar permanente na história da Antropologia como criador do objeto "sistema de parentesco", dos métodos da disciplina que o estuda, e das hipóteses principais que ainda hoje alimentam a disciplina. Foi apoiada em dados de pesquisa de campo original em escala mundial, feita diretamente por Morgan ou sob sua orientação. Contudo, com essa obra, Morgan não seria incluído entre os antropólogos "evolucionistas", porque sua teoria do progresso das formas de família humana da "promiscuidade" à "civilização" foi acrescentada por ele em uma segunda versão da obra, enviada ao editor em 1868.

\section{As duas versóes dos Sistemas e suas respectivas teorias}

Systems of Consanguinity and Affinity in the Human Family foi publicado originalmente em 1871, como o volume 17 da série Contributions to Knowledge do Instituto Smithsoniano, imediatamente após A Origem da Civilização de John Lubbock (1870) e logo antes de Cultura Primitiva de Edward B. Tylor ([1871] 2010). O manuscrito havia sido submetido por Morgan ao secretário do Instituto Smithsoniano em 1865, ano que apareceram Pre-historic Times de Lubbock, Researches into the Early History of Mankind de Tylor e Primitive Marriage 
de John McLennan, e submetido novamente em 1868 ao editor que havia exigido cortes e modificaçóes na primeira versão ${ }^{1}$. Entre a primeira e a segunda versão, a principal diferença foi a inclusão do capítulo final, no qual aparece a explicação dos fatos apresentados no livro por meio de uma sequência histórica "conjetural" de formas de família.

Houve, portanto, duas versōes de Systems of Consanguinity and Affinity of the Human Fami$y^{2}$. A primeira versão tinha o objetivo principal de provar a origem asiática dos índios americanos. A prova decisiva da tese era a demonstração da unidade entre os "planos" das terminologias de parentesco sêneca-iroquesa e tamil (dravidiana) ${ }^{3}$. Para essa prova, Morgan criou um método inteiramente novo, e que pode ser legitimamente chamado de estrutural: a comparação não dos termos de parentesco, mas dos "sistemas de relaçôes" que conectam entre si os termos contidos nas terminologias de parentesco. O resultado principal dessa análise foi a demonstração de que os "sistemas de relaçóes" de diferentes povos, tabulados com detalhamento e abrangência jamais vistos desde entáo, podiam ser agrupados em dois grandes tipos: os "sistemas descritivos" e os "sistemas classificatórios", sendo os primeiros característicos de todos os povos indígenas norte-americanos (exceto os Esquimó), bem como dos povos da Índia do Sul, da China, do sudeste asiático e do Pacífico (os dados de Morgan sobre o Japáo náo eram bons, e ele não recebeu dados da África nem da América do Sul). Esse resultado, embora representasse para Morgan a evidência da unidade dos povos indígenas norte-americanos, e de sua unidade com povos asiáticos, colocava um enigma.

Tratava-se de explicar a própria existência dos "sistemas classificatórios", que eram, de um lado, característicos de povos não civilizados e, por outro lado, eram mais artificiais, mais elaborados e mais distantes da "natureza da descendência" do que os "sistemas descritivos" dos povos "civilizados". A solução para a existência dos "sistemas classificatórios" foi proposta por Morgan em um artigo publicado separadamente em 1868 com o título A Conjectural Solution of the Origin of the Classificatory System of Relationship. É essa uma das duas obras de Lewis Morgan que Darwin cita com respeito em The Descent of $\mathrm{Man}^{4}$ (Darwin, [1871] 2004, p. 170, nota 35 ; p. 655, nota 5; p. 661, nota 14). Adam Kuper (1985) atribuiu a nova teoria à influência do evolucionismo social inglês de McLennan e de Lubbock sobre Lewis Morgan, mas Elisabeth Tooker (1997) e Thomas Trautmann (2010) refutam essa atribuição, com apoio em fontes primárias que Kuper náo consultou. Segundo eles, Morgan chegou à sua teoria do progresso das instituiçóes de família graças às sugestóes insistentes do amigo Mcllvain, e sob o impacto da substituiçáo da cronologia bíblica, que dava seis milênios para a história humana, pela nova cronologia geológica e paleontológica que adicionava a ela no mínimo centenas de milênios. Esse espaço a preencher, diz Trautmann, é o terreno para cujo preenchimento a "solução conjetural" é oferecida. Nela, em vez de sistemas coexistentes e que se irradiam historicamente através dos continentes, há uma sequência linear de "formas de família" que explicam a diversidade dos sistemas terminológicos (Trautmann, 1987; 2010).

Morgan insistiu, porém, na introdução à versão publicada em 1871, que o verdadeiro valor de seu livro estava em seu "método" e em seus "dados". Nas palavras do próprio Morgan, "as tabelas são os resultados principais" da sua investigação. Morgan pede enfaticamente para que pesquisadores futuros continuem a investigar os "sistemas" com novos casos, e ressalta sua convicção do valor metodológico do "novo instrumento da etnologia" que havia criado:

sua importância e seu valor vão muito além de qualquer uso que o escritor possa ser capaz de

cadernos de campo, São Paulo, n. 19, p. 309-322, 2010 
3 I 2 Mauro William Barbosa de Almeida

indicar no presente para seu conteúdo. Se elas puderem ser aperfeiçoadas, e os sistemas das naçóes que não estão representadas puderem ser fornecidos, o valor delas será enormemente aumentado (Morgan, [1871] 1997, p. 8).

Se essas tabelas bastarem para demonstrar a utilidade de sistemas de relacionamento para a realização de investigaçôes etnológicas, um dos principais objetivos desta obra terá sido atingido. (...) As tabelas, portanto, são apenas o começo da obra, se este novo instrumento da etnologia for um convite ao teste da crítica (Op. cit., p. 9).

Esse texto, já pronto em maio de 1868, traz em nota o apelo de Lewis Morgan:

Toda pessoa interessada no avanço do objeto, que procure obter o sistema de qualquer nação não representada nas tabelas, ou que corrija ou complete qualquer lista defeituosa nelas contida, prestará um serviço especial ao autor (Op. cit., p. 9).

As tabelas ocupam mais de 200 páginas de terminologias de parentesco, e são comentadas em 450 das 600 páginas do livro inteiro. Abrangem 39 povos das famílias semítica, ariana e uraliana, 80 povos das famílias ganowaniana (índios norte-americanos, menos Esquimó, com os Sêneca-iroqueses como caso representativo) e Esquimó, e 18 povos das famílias turaniana (falantes de línguas dravidianas do sul da Índia, com o Tamil como caso representativo) e malaia, num total de 147 casos. Exceto pelos dados sobre o sistema romano antigo e outros sistemas indo-europeus apoiados em fontes secundárias, os dados vêm dos questionários de Lewis Morgan, enviados por correio ou entregues em pessoa, ou de sua própria pesquisa de campo.

\section{A invençáo do parentesco e o método comparativo-estrutural}

Em que consiste o método que organiza essas tabelas, ao qual Morgan atribuiu tanta importância? Levando em consideração a dificuldade de acesso aos Systems of Consanguinity and Affinity of the Human Family, usarei um exemplo retirado de uma tabela desta obra que foi republicada por Morgan em seu livro mais conhecido, que é $A$ Sociedade Antiga.

A tabela abaixo talvez seja suficiente para ilustrar o conceito e o método. Na coluna 1, encontram-se "relações de família" básicas (Ego/Pai, Ego/Filho) ou compostas de relações básicas (Ego/Irmão do Pai, Ego/Irmão da Mãe, Ego/Filho do Irmão, Ego/Filho da Irmã). Nas colunas seguintes, encontram-se os termos de parentesco associados em diferentes línguas (Sêneca-Iroquês, Tamil, Inglês) a cada uma dessas relaçóes. A coluna 1 contém uma lista, potencialmente infinita, de relaçôes compostas de relaçóes básicas, enquanto as colunas 2, 3 e 4 indicam os termos vernáculos, em número finito, associados às relações da primeira coluna. O resultado é a visibilização de "planos" ou "sistemas de relacionamento". Assim, as colunas 2 e 3 exibem um mesmo "sistema de relacionamento", que contrasta com o "sistema de relacionamento" exibido pela coluna 4. O que está sendo comparado não são termos, e sim relaçóes entre termos. Os "planos" de Morgan podem ser chamados, segundo Trautmann $(1981,2010)$, de sistemas semânticos.

A descoberta da existência de uma multiplicidade de "planos" para agrupar um número virtualmente infinito de relaçóes de parentesco (exemplificados na coluna 1) em um conjunto finito de categorias terminológicas (exemplificados nas colunas 2, 3 e 4) foi aquela que Morgan considerou como sua grande contribuiçáo para a etnologia. Com a 
descoberta da pluralidade de sistemas semânticos que organizam diferentemente as relaçóes de consanguinidade, Morgan desnaturalizou os "sistemas de parentesco", precisamente ao demonstrar que os "sistemas classificatórios" são artifícios da "inteligência humana”. Passemos ao exemplo.

Tabela 1. Um fragmento dos sistemas Sêneca-Iroquês, Tamil e Inglês.

\begin{tabular}{|c|c|c|c|c|}
\hline \multirow[b]{2}{*}{0} & \multirow[b]{2}{*}{1} & \multicolumn{2}{|c|}{$\begin{array}{l}\text { Sistemas } \\
\text { Classificatórios }\end{array}$} & \multirow{2}{*}{\begin{tabular}{|l} 
Sistemas \\
Descritivos \\
4
\end{tabular}} \\
\hline & & 2 & 3 & \\
\hline & $\begin{array}{l}\text { Relações (ego } \\
\text { masculino) }\end{array}$ & $\begin{array}{l}\text { Sêneca- } \\
\text { Iroquês }\end{array}$ & $\begin{array}{l}\text { Tamil } \\
\text { (dravidiano) }\end{array}$ & Inglês \\
\hline 7 & Ego/PAl & \multirow[b]{2}{*}{ hä'-nih } & \multirow[b]{2}{*}{ takkappan } & my father \\
\hline 53 & $\begin{array}{l}\text { Ego/IRMAO DO PAl } \\
\text { (mais velho) }\end{array}$ & & & \multirow[t]{2}{*}{ my uncle } \\
\hline 90 & Ego/IRMAO DA MAE & hoc-no-se & En maman & \\
\hline 9 & Ego/FILHO & \multirow{2}{*}{ ha-ah-wuk } & \multirow{2}{*}{ En makan } & my son \\
\hline 23 & $\begin{array}{l}\text { Ego/FILHO DO } \\
\text { IRMAO }\end{array}$ & & & \multirow{2}{*}{ my nephew } \\
\hline 31 & Ego/FILHO DA IRMA & $\begin{array}{l}\text { hay-ya-wan- } \\
\text { da }\end{array}$ & En & \\
\hline
\end{tabular}

Fonte: Comparative Table of the System of Relationship of the Seneca-Iroquois Indians of New York, and of the People of South-India speaking the Tamil Dialect of the Dravidian Language (Morgan, [1871] 1997; [1877] 1985). Os números da coluna 0 são os da tabela original, que contém 218 linhas e mais detalhes em cada linha.

A tabela ilustra o resultado principal de Morgan: existem dois sistemas fundamentalmente diferentes de terminologias de parentesco: o "descritivo" e o "classificatório". No interior dessas subdivisóes, os sistemas classificatórios incluíam a família malaio-polinésia (Pacífico), a família turaniana (sul da Índia), e a família ganowaniana (índios da América do Norte, menos os Esquimó). Essa subdivisão, apoiada em uma análise minuciosa de indicative features de cada sistema, permanece com novos rótulos como parte de toda a discussão clássica de problemas de parentesco até nossos dias. Isso é ilustrado na Tabela 2 , também muito simplificada.
Tabela 2. Sistemas na terminologia de Morgan e na terminologia contemporânea

\begin{tabular}{|l|l|l|l|}
\hline \multirow{5}{*}{$\begin{array}{l}\text { Sistemas } \\
\text { Classificatórios }\end{array}$} & $\begin{array}{l}\text { América do Norte } \\
\text { América do Sul }\end{array}$ & $\begin{array}{l}\text { Ganowaniano } \\
\text { (tipo: Sêneca- } \\
\text { Iroquês) }\end{array}$ & $\begin{array}{l}\text { Iroquês, Crow, } \\
\text { (exemahal }\end{array}$ \\
\cline { 2 - 4 } & $\begin{array}{l}\text { Sul da Índia } \\
\text { Austrália } \\
\text { América do Sul }\end{array}$ & $\begin{array}{l}\text { Turaniano (tipo: } \\
\text { Tamil) }\end{array}$ & $\begin{array}{l}\text { Dravidiano, } \\
\text { Kariera, } \\
\text { Kaxinawá }\end{array}$ \\
\cline { 2 - 4 } & $\begin{array}{l}\text { Pacífico } \\
\text { Sistemas descri- }\end{array}$ & $\begin{array}{l}\text { Malaio (tipo: } \\
\text { Havaiano) }\end{array}$ & Havaiano \\
\hline tivos & Médio & $\begin{array}{l}\text { Ariano-Semítico- } \\
\text { Uraliano }\end{array}$ & Esquimó \\
\hline
\end{tabular}

Nota: Na classificação proposta por Murdock (1949), Crow e Omaha são subcategorias do sistema "iroquês", que inclui também 0 sistema "dravidiano". Este será distinguido do sistema iroquês a partir de Lounsbury (a distinção já era feita por Morgan). A coluna da direita é meramente ilustrativa, sem refletir a variedade de tipologias atuais (e.g. Murdock distingue o sistema "sudanês" do "esquimó"), entre sistemas que distinguem parentes colaterais de parentes lineais ("descritivos" na classificação de Morgan).

A Tabela 2 visa mostrar que, para além das diferenças de denominação, Morgan identificou os padróes com que a etnologia posterior trabalhou no século seguinte. Mas a tabela indica também refinamentos e descobertas. Uma delas refere-se à fundamentação da distinção, já feita por Morgan, entre os sistemas ganowaniano (iroquês) e turaniano (tamil-dravidiano), e entre sistemas dravidianos e kariera (que se deve em parte a um discípulo de Morgan). Outro refinamento refere-se às características que distinguem os sistemas crow e omaha no interior do tipo iroquês ${ }^{5}$. Essas elaborações devem-se a Murdock (1949), Dumont (1953), Lounsbury ([1964] 1969) e ainda outros. Mas muitas das distinçóes em jogo já haviam sido apontadas por Morgan em sua obra de 1871.

Pode-se considerar que essa linha de investigação esteja morta hoje em dia? A resposta é não. Em primeiro lugar, porque o método acima está na base das abordagens de teóricos como Goodenough ([1865] 1969), Lounsbury 
([1964] 1969), Trautmann (1981), Viveiros de Castro (2002), para citar apenas alguns exemplos de análises de terminologias de parentesco que podem ser chamadas legitimamente de estruturais. Em segundo lugar, o método do estudo comparativo de textos e de vocabulários aplicado para rastrear trajetos migratórios da "família humana" foi revitalizado nos tempos modernos por Joseph Greenberg, "o principal taxonomista contemporâneo" de línguas na opinião de Cavalli-Sforza, pesquisador de genética de populaçóes (Cavalli-Sforza, 2002, 2003).

\section{Em busca da explicação para a estrutura: as "causas externas"}

Restava o enigma da explicação para a própria existência dos sistemas classificatórios, e para a passagem destes para sistemas descritivos. Há uma primeira teoria a respeito desse problema já nas primeiras páginas dos Systems. Ei-la nas palavras de Morgan:

Há um poderoso motivo que poderia, sob certas circunstâncias, levar à derrubada da forma classificatória e à sua substituição pela descritiva; ele surgiria, porém, após o surgimento da civilização. Trata-se da herança do patrimônio territorial (estates). Pode-se postular que o laço do parentesco, entre naçóes não civilizadas, é uma forte influência para a proteção mútua de pessoas relacionadas. Entre tribos nômades, especialmente, a respeitabilidade do indivíduo era avaliada, em grande medida, pelo número de seus parentes. Quanto mais amplo o círculo de parentes, maior a certeza de segurança, já que eles eram os guardióes naturais de seus direitos e os vingadores de suas ofensas. Quer por desígnio ou não, a forma de consanguinidade turaniana organizava a família com base na escala máxima do número de seus membros (Morgan, [1871] 1997, p. 14).
Morgan afirma aqui que as funçôes de "guardião de direitos" que cabem ao Estado na "sociedade civilizada" são realizadas, nas sociedades sem Estado, pelo "laço de parentesco" (bond of kindred). Segue-se que o tamanho do grupo de parentesco tende, nessas sociedades, à "escala máxima numérica". A forma classificatória de consanguinidade, identificando pais e irmãos dos pais, e identificando filhos e filhos de irmãos, seria um método para maximizar o tamanho de grupos de parentesco, os quais cumpririam certas funçôes do Estado em sociedades sem Estado. Por outro lado, continua Morgan,

uma mudança gradual de uma condição nômade para uma condição civilizada demonstra-se como o teste mais severo ao qual um sistema de consanguinidade poderia ser submetido. A proteção da lei, ou do Estado, substituiria a da parentela; (...) os direitos de propriedade poderiam influenciar com força efetiva o sistema de relações (Op. cit., p. 14).

Como exemplo do sistema classificatório, Morgan cita o caso da sociedade tamil, "where my brother's son and my cousin's son are both my sons". Essa forma de consanguinidade, diz Morgan, teria um propósito útil ao aproximar "o laço de parentesco", isto é, ao ampliar o número de pessoas tratadas como "filhos". Contudo, diz Morgan, "no sentido civilizado seria manifestamente injusto colocar qualquer destes filhos colaterais em pé de igualdade com meu próprio filho para a herança de meu patrimônio (estate)" ${ }^{6}$.

Notemos, em primeiro lugar, que essa tese tornou-se parte integrante da antropologia dos sistemas políticos de sociedades sem Estado, desenvolvida pela escola britânica de Antropologia Social e apoiada em parte na teoria de Morgan sobre o papel de grupos de parentesco maximizados por meio dos sistemas classificatórios ${ }^{7}$. A escola britânica reconheceu de modo mais explícito seu débito, quanto a essa tese, para com 
Henry Maine, cuja obra Ancient Law ([1861] 1986) foi dedicada inteiramente a elaborar a tese de que a passagem da "barbárie" para a "civilização" foi marcada pela transição entre um sistema de direito baseado nos laços pessoais de status a um sistema de direito baseado nos laços de contrato. Em suma, trata-se de uma teoria funcionalista para explicar os sistemas classificatórios.

A passagem de Morgan citada acima contém o cerne da nota de rodapé que Engels apôs ao Manifesto do Partido Comunista, publicado originalmente em 1848, ao reeditá-lo em 1888. Logo após a frase que afirma que "a história de toda sociedade até agora é a história da luta de classes", Engels acrescenta:

Isto é, toda a história escrita. Em 1847, a pré-história da sociedade, a organização social existente antes da história registrada, era praticamente desconhecida. Desde então, Haxthausen descobriu a propriedade comum da terra na Rússia, Maurer provou que ela é o fundamento social de que partiram todas as raças teutónicas da história e, pouco a pouco, verificou-se que as comunidades aldeãs são ou foram a forma primitiva de sociedade em toda a parte, da Índia à Irlanda. A organização interna desta primitiva sociedade Comunista foi posta a nu, na sua forma típica, pela descoberta culminante feita por Morgan da verdadeira natureza da gens e da sua relação com a tribo. Com a dissolução destas comunidades primevas, a sociedade começa a diferenciar-se em classes separadas e finalmente antagônicas. Tentei reconstituir este processo de dissolução em A Origem da Familia, da Propriedade Privada e do Estado (Nota de Engels à edição inglesa do Manifesto do Partido Comunista, de 1888).

A sequência de invençôes tecnológicas, formas de família, formas de governo e instituiçóes de propriedade, destacada por Engels na sua reelaboração da Sociedade Antiga de Morgan, prescinde de maior comentário, sendo a parte mais conhecida do legado de Morgan ${ }^{8}$.
Cabe ainda notar que Morgan considerou várias "causas externas" para a existência das terminologias classificatórias, antes de apresentar sua sequência progressiva de formas de família, no capítulo dos "Resultados Gerais" que conclui seu livro ([1871] 1997, p. 467510). No fecho de sua grande obra, Morgan discute minuciosamente várias hipóteses que agrupamos como "explicações sociológico-funcionais". Estas explicaçôes incluem: o papel dos laços de parentesco para proteção mútua, o sistema de linhagens, a poligamia e a poliandria (Op. cit., p. 467-479). As três últimas hipóteses foram testadas estatisticamente por George Murdock em seu Social Structure de 1949. É a partir da seção IV deste capítulo, após indicar que nenhuma dessas explicaçóes abrange todos os fatos observados, que Morgan apresenta finalmente sua "soluçáo conjetural",

... sob a hipótese da existência de uma série de costumes e instituiçóes antecedentes a um estado de casamento entre pares individuais, nos quais o costume havaiano se inclui (Op. cit., p. 474).

Em suma, Morgan estava longe de ignorar explicações históricas com apoio documental (casos da gens romana e grega), ou explicaçóes funcionais e sincrônicas, apoiadas em dados da etnografia de primeira mão. É assim um tanto injusto que Radcliffe-Brown (1952) utilize, para criticar a "história conjetural" como explicação de terminologias classificatórias, uma explicação sincrônico-funcional baseada na organização de linhagens, sem mencionar que Morgan foi o primeiro a propor e discutir precisamente essa explicação ${ }^{9}$. Com efeito, como disse Trautmann, "certos aspectos do conhecimento recebido na antropologia são profundamente marcados por Morgan, quer saibamos disso ou não" (Trautmann, 2010, p. v). Para concluir esse sobrevoo da presença de Morgan na teoria contemporânea, falta considerar o 
nexo entre Morgan e a teoria lévi-straussiana do parentesco, para além do objeto e do método "estrutural". A resposta passa por um costume que Morgan ignorou, mas que Rivers ([1910] 1991) invocou, para explicar a peculiaridade que distingue o sistema tamil (dravidiano) do sistema iroquês: o casamento de primos cruzados. Sobre esse ponto cego na análise de Morgan, eis o que diz Trautmann:

Morgan deixou de reconhecer o papel do casamento de primos cruzados no sistema dravidiano, e foi aqui particularmente obtuso já que suas fontes de informação sobre o sistema dravidiano indicaram claramente a regra e sua conexão com a terminologia. Como argumentei, foi uma coincidência fatídica o fato de que o próprio Morgan tenha se casado com a filha do irmão de sua mãe, uma prima cruzada em sistemas onde a regra existe, fato que explica, a meu ver, seu ponto cego sobre o assunto ao tratar dos dravidianos, erroneamente identificados com os iroqueses (Trautmann, 2008, p. 324).

Como se sabe, toda a teoria das "estruturas elementares do parentesco" pode ser entendida como uma teoria da aliança de casamento entre primos cruzados. A teoria, porém, não funciona para os sistemas de parentesco dos índios norte-americanos aos quais correspondem terminologias "iroquesas" (e em particular seus subcasos crow e omaha). Lévi-Strauss (1967) forneceu, assim, uma justificativa profunda para a dicotomia aguda que separaria as "estruturas elementares de parentesco" (exemplificadas pelos sistemas dravidianos) das "estruturas complexas" (exemplificadas pelos sistemas "iroqueses", particularmente em suas variantes crow e omaha): a existência ou ausência de uma regra prescritiva de casamento. Cabe lembrar que a identificação "errônea" entre o sistema iroquês e dravidiano não vem de Morgan, que separou nitidamente o sistema ganowaniano (cujo tipo é o iroquês) do sistema turaniano (cujo tipo é o tamil), e indicou claramente o locus da diferença entre os dois, embora se afirmando incapaz de explicá-la (Morgan, [1871] 1997, p. 398). A "identificação" entre esses dois sistemas foi obra das tipologias de Lowie ([1929] 1968) e Murdock (1949), na qual iroquês e dravidiano de fato confundem-se em um único tipo, até que Lounsbury (1964, nota 16) apontou a diferença, tendo lido certamente a observação explícita de Morgan sobre o assunto.

Entende-se que Systems possa ter servido de epígrafe tanto ao tratado culturalista comparativo de Murdock como ao tratado estruturalista de Lévi-Strauss, e que possa ter contribuído tanto para a teoria materialista da história de Marx e Engels assim como para a teoria funcional-estrutural de sociedades sem Estado formulada por Radcliffe-Brown e Evans-Pritchard. Compreende-se também que Tooker apresente essa obra como "one of the most remarkable of all anthropological studies” (Tooker, 1997, p. vii), e que Trautmann (2010, p. v) tenha afirmado que Morgan continua "good to think" até nossos dias.

A influência de Morgan sobre a Antropologia exerceu-se desde cedo, e é ilustrada pelos debates com John McLennan sobre o parentesco classificatório, e pela teoria de Edward B. Tylor sobre a conexão entre o casamento de primos cruzados e o parentesco classificatório (Tooker, 1971). Talvez essa convergência esteja na raiz da opinião dominante que é a que inclui Morgan entre os "evolucionistas vitorianos", em uma posição caudatária de Lubbock, McLennan e Tylor, agrupando todos ao depósito de velharias teóricas que são mencionadas, mas não estudadas seriamente. Esse juízo é ilustrado sarcasticamente por Adam Kuper, que afirmou em 1993:

A lâmpada de Edison realmente funcionava, e talvez as patentes ainda valham alguma coisa, ao passo que as fantasias intelectuais de Morgan, McLennan, e [Max] Müller conservam 
pouco valor contemporâneo, se é que ainda têm algum (Kuper, 1993).

As obras de Lubbock, McLennan, Tylor e Morgan situam-se de fato no período que vai da publicação de A Origem das Espécies ([1859] 2009) ao aparecimento de The Descent of Man ([1871] 2004). Morgan admirava a obra de Darwin, que visitou na Inglaterra. De acordo com o Carl Resek, aliás, foi Darwin quem encaminhou Morgan para um encontro com John McLennan em Londres, que por sua vez o colocou em contato com os evolucionistas sociais Lubbock, McLennan e Henry Maine (Resek, 1960, p. 125). O consenso entre historiadores é, contudo, que, a despeito de sua admiraçáo por Darwin, e de sua decidida posição monogenista (e, portanto, contrária ao antidarwinista Agassiz), Morgan não era um adepto do evolucionismo darwiniano. Ele descreveu uma história humana na longa duraçáo da nova cronologia como uma história de progresso através de invençôes, mas não é claro que aceitasse uma origem não humana para a humanidade. A questão é sujeita a debate, porque Morgan retirou de uma versáo preliminar dos Systems, a pedido de seu amigo McIlvaine, uma formulação que sugeria um apoio explícito a Darwin. Outro ponto relevante é a recusa de Morgan a estabelecer uma fronteira absoluta entre a espécie humana e os "mudos" (mutes), ou animais como formigas e castores, que considerava como dotados de inteligência e da capacidade para elaborar obras em resposta a desafios técnicos e ambientais.

$\mathrm{Na}$ Antropologia inglesa, a problemática colocada por Morgan foi introduzida por W. H. Rivers ([1910] 1991), e Meyer Fortes homenageou Morgan para a Antropologia Social em Kinship and the Social Order: The Legacy of Lewis Henry Morgan ([1969] 2005). Na América do Norte, a imagem de Lewis Morgan foi marcada pelas críticas de Alfred Kroeber ([1909] 1969) ao próprio conceito de "sistema classificatório" e, sobretudo, de Robert Lowie em The History of Ethnological Theory (1937). Sobre a crítica cerrada de Kroeber e de Lowie a Morgan é difícil resistir a citar Trautmann:

Engels criticou os antropólogos ingleses por atacarem Morgan e ao mesmo tempo plagiarem seus resultados. Isso mudou com Rivers, a partir de quem a antropologia inglesa adotou os métodos de Morgan, mas poderia aplicar-se aos boasianos na América do Norte (Trautmann, 2008, p. vii).

Leslie White (1951, 1957, 1958, 1959) dedicou-se, na América do Norte, a restaurar a reputação intelectual de Morgan contra a diminuição efetuada pelos boasianos, mas talvez a defesa de Morgan por Leslie White, acompanhada de uma versão radical de evolucionismo linear, e de simpatia pelo marxismo, crítica aos boasianos, tenha piorado a imagem de Morgan na academia norte-americana, ao invés de melhorá-la. Em 1949, Lévi-Strauss dedicou a Morgan as Estruturas Elementares do Parentesco, e George Murdock incluiu Morgan entre os homenageados na abertura da obra Social Structure, publicada também em 1949. Essas duas obras, saídas no mesmo ano que Social Evolution de Leslie White, também publicada em 1949, assinalavam três retomadas de temas e problemas deixados por Lewis Morgan, de perspectivas muito diferentes: o culturalismo de Murdock, o estruturalismo de Lévi-Strauss e o evolucionismo social de Leslie White.

Um outro marco na retomada de Lewis Morgan foram os estudos de Floyd Lounsbury ([1964] 1969) sobre terminologias de parentesco de índios norte-americanos. Lounsbury usa os dados e o enfoque de Morgan como instrumentos da análise semântico-estrutural. Dessa forma, na década de 1950, o legado de Morgan ressurge associado ao mesmo tempo à retomada do evolucionismo cultural por White, ao teste estatístico e sincrônico de suas 
hipóteses por Murdock, e à fundação de duas ciências: a Antropologia Estrutural e a Semântica Estrutural de Goodenough ([1865] 1969) (também conhecida como análise componencial) e de Lounsbury ([1964] 1969).

Em 1972, porém, o capítulo de David Schneider dedicado ao centenário de publicaçáo de Sistemas de Consanguinidade e Afinidade anunciava que Lewis Morgan era o fundador da ciência de um objeto inexistente: o parentesco. Na Inglaterra, Rodney Needham (1971) fez uma declaração semelhante. A desconstruçáo de Schneider teve enorme sucesso, mas curiosamente ela não resultou no fim dos estudos de parentesco: em vez disso, ela marcou a divisão desse campo em estudos "clássicos" de parentesco, e os "novos estudos de parentesco". American Kinship (1980), de David Schneider, bem como After Nature (1992), de Marilyn Strathern, são exemplos da direção tomada pelos "novos estudos de parentesco", sendo uma marca distintiva deles a ausência completa de genealogias, terminologias de parentesco e de regras de casamento. Por outro lado, a tradição dos "velhos estudos" continuou viva, mais na França e no Brasil do que na Inglaterra e nos EUA. Tanto na França como no Brasil, a continuidade dos estudos "clássicos" ou morganianos de parentesco deve-se à sua redefinição da problemática feita por Lévi-Strauss, e de questóes colocadas por Louis Dumont, Lounsbury e por Trautmann. De fato, a partir de Louis Dumont (1975) e de Lousnbury ([1964] 1969) acende-se o debate sobre uma questão que foi aflorada por Lewis Morgan nos Sistemas de Consanguinidade e Afinidade: qual é a diferença entre o "sistema sêneca-iroquês" e o "sistema tamil (dravidiano)"? Esse problema, ao qual se juntou o das diferenças entre o sistema dravidiano e o sistema kariera (inicialmente estudado na Austrália por um discípulo de Morgan), juntou-se ao tema espinhoso das terminologias sistemas "crow-omaha".

$\mathrm{Na}$ América do Sul, Joana Overing (ex-Kaplan) (1975) iniciou a aplicação do conceito dumontia- no de "sistemas dravidianos" a terminologias de parentesco ameríndios, e Eduardo Viveiros de Castro (2002) liderou um vasto projeto coletivo de estudos etnológicos sobre parentesco em que o tema da "afinidade" é central. Um balanço da questão foi apresentado em uma publicação de 1998 organizada por Maurice Godelier, Thomas Trautmann e Tjon Sie Fat (1998). Em suma, nada indica que o tema do parentesco esteja morto, e pode-se dizer que ele é um campo particularmente vivo no Brasil ${ }^{10}$. No Brasil, aliás, a leitura evolucionista de Morgan também inspirou a visão teórica exposta por Darcy Ribeiro (1972) em seus estudos sobre o processo civilizatório nas Américas e seu efeito sobre os índios do Brasil. Há muita semelhança, aliás, entre a combinaçáo um tanto incoerente da fé de Lewis Morgan no progresso e sua admiração ilimitada pelos índios iroqueses, que segundo sua teoria do progresso estavam no estágio pré-civilizado, e a fé positivista de Rondon no progresso e sua postura humanista face aos índios, posição ecoada por Darcy Ribeiro em sua própria versão do evolucionismo de Leslie White e de Julian Steward. Morgan descreveu o sistema classificatório como "complexo em sua estrutura, elaborado em suas discriminaçôes, e opulento em sua nomenclatura” ([1871] 1997, p. 471).

Continua Morgan:

Pelas excessivas e intrincadas especializaçôes corporificadas no sistema [classificatório], ele poderia ser considerado como de difícil uso prático; contudo, uma de suas características mais singulares é que ele é complicado sem obscuridade, diversificado sem confusão, e é compreendido e aplicado com máxima facilidade. (...) Nenhum outro caracteriza propriamente uma estrutura cujo arcabouço é tăo completo, e cujos detalhes são tão rigorosamente ajustados (Op. cit., p. 472).

É evidente nessas páginas a admiração de Lewis Morgan pelo sistema de parentesco iroquês e seus análogos. Essa admiração, contras- 
tando agudamente com o preconceito vitoriano, tem paralelo apenas na admiração de Morgan pela organização social iroquesa, expressa desde 1859 na Liga dos Iroqueses às páginas finais da Sociedade Antiga em 1877. Mais descentralizado e complexo do que o centralismo monárquico europeu que Morgan detestava, o sistema iroquês foi exaltado por Morgan como exemplar (e tem sido apontado como precursor da democracia federalista norte-americana). Isso significava, porém, que a ordem do progresso que ia da barbárie à civilização caminhava do complexo para o simples; o fechamento da fronteira era ao mesmo tempo a simplificação dos intrincados sistemas classificatórios que "maximizavam os laços de parentesco", e a destruiçáo do federativismo democrático iroquês. A civilização também representou, aliás, o fim da elaborada cultura material do castor norte-americano, que Morgan não diferenciava em essência da cultura material dos indígenas iroqueses, já que incluía os "mudos" na categoria de seres dotados de inteligência e capacidade de invenção.

Se devemos falar de um evolucionismo social em Morgan - que usou sempre a noção de progresso, e não de evolução -, trata-se de uma versão peculiar de evolucionismo social. Assim como as estepes russas para Kropotkin, as pradarias americanas não combinavam, para Morgan, com a "luta pela vida". Mas Morgan assistiu ao fechamento da fronteira americana, e tomou parte dela como advogado de ferrovias. Face a essa história real da propriedade privada, a linha do tempo progressivo que leva da barbárie à civilização adquiria para ele um viés negativo, expresso em páginas célebres da A Sociedade Antiga que vale a pena evocar:

A mera trajetória da propriedade não é o destino final da humanidade, se o progresso continuar a ser a lei do futuro como tem sido a lei do passado. O tempo que transcorreu desde que a civilização começou é apenas um fragmento da duração passada da existência humana; e é apenas um fragmento das eras que virấo. A dissolução da sociedade tem boas chances de ser o termo final de uma trajetória da qual a propriedade é o fim e o objetivo, porque tal trajetória contém os elementos da autodestruição. A democracia no governo, a fraternidade na sociedade, a igualdade de direitos e de privilégios, e a educação universal, prenunciam o plano superior da sociedade para qual a experiência, a inteligência e o conhecimento estão conduzindo firmemente. Este será um renascimento, em forma superior, da liberdade, da igualdade e da fraternidade das antigas gentes (Morgan, [1877] 1985, p. 552).

É a visão que já se anuncia em um discurso dirigido por Morgan para uma associação de trabalhadores já em 1852, e que marca a distância entre o evolucionismo social vitoriano e a noção ambígua de progresso em Morgan.

\section{Lewis Morgan: 140 Years of Systems of Consanguinity and Affinity of the Human Fa- mily (1871-2011)}

abstract Lewis Henry Morgan is usually grouped with McLennan, Lubbock and Tylor as one of the cabinet evolutionists whose work is mentioned at the beginning of anthropology courses, but whose reading is not recommended. In fact, Morgan was a pioneer in fieldwork research, whose first theoretic project was to prove the unity of humanity and the Asiatic origin of Amerindian peoples, employing a method that can be legitimately named structural. Morgan's evolutionism, or what he called as the "conjectural solution" of the diversity of kinship terminologies through a progressive sequence of family forms was an addendum to his monumental work Systems of Consanguinity and Affinity of the Human Family, published in 1871. The "conjectural solution" is the focus of his best known work, that is Ancient Society published in 1877. Even though, this second work had not been published, Morgan deserves being recognized as the creator of the 
object "Kinship System", of having created a system to study it and, of having performed an effort of comparative research without pair until today. Lewis Morgan was a pioneer in the research on political systems, of architecture and of commensalism of Amerindian indigenous people, besides being a naturalist that defended the "muted" beings, to whom he attributed intelligence equal in nature to that of beings endowed with speech.

keywords Morgan. Anthropology. Kinship. Evolutionism. Human History.

\section{Notas}

1. Em 1871, Morgan estava preocupadíssimo com a demora de seis anos na publicação do livro, contando a partir de 1865 , e de três anos, contando a partir de 1868 (Tooker, 1997, p. vii).

2. O comentário detalhado sobre a diferença entre as duas versóes está em Trautmann, 2008, Apêndice III.

3. A comparação direta está na tabela não numerada dos Sistemas, cujo título aparece como Comparison of the System of Relationship of the Seneca-Iroquois with that of the Tamil People of South America (Morgan, 1871, p. 511-514). A indicação "América do Sul" em vez de "Índia do Sul” é um lapso profético já que, embora Morgan nunca tenha trabalhado com dados sobre índios da Amazônia, estes viriam a tornar-se terreno paradigmático de "dravidianato" (Overing, 1975; Silva, 1995; Viveiros de Castro, 2002).

4. A outra obra de Morgan citada por Darwin é The American Beaver and His Works, também publicada em 1868.

5. Morgan distinguiu "ganowaniano" e "turaniano", mas viu os dois sistemas como sendo "idênticos" em seus traços essenciais, exceto por uma divergência que não soube como explicar: no sistema tamil, a filha da minha prima cruzada (sendo eu homem) é chamada de "minha filha", enquanto no sistema Iroquês o termo apropriado é "minha sobrinha” (Morgan, [1871] 1997, p. 391).

6. À página 14 de Systems, Morgan afirma que na sociedade tamil "my brother's son and my cousin's son are both my sons". De fato, esse "traço indicativo" aplica-se ao sistema sêneca-iroquês, mas não ao sistema dravidiano (se tomarmos
Ego masculino e "cousin" como o primo cruzado masculino). É o próprio Morgan quem afirma este último ponto, à página 391: "The children of my male cousins, Ego a male, are my nephews and nieces; of my female cousins are my sons and daughters", advertindo em seguida: "esse é o único detalhe em que [a forma tamil] difere substancialmente da forma sêneca-iroquesa”. A aparente contradição pode indicar a sobrevivência de uma versão anterior no manuscrito final.

7. Sobre a tendência à maximização dos números dos parentes, lembremos que a expansão territorial nuer foi atribuída ao tamanho de seus grupos guerreiros, por sua vez explicado pelo sistema de linhagens (Kelly, 1985).

8. Acompanhamos aqui, por comodidade de exposição, a posição segundo a qual a teoria marxista da história é uma teoria funcionalista (Cohen 1978).

9. Trata-se da crítica ao método da "história conjetural" em The Study of Kinship Systems, datado de 1941 (Radcliffe-Brown, 1952). Radcliffe-Brown refere-se aos Systems como um "monumento de erudição e de pesquisa paciente na coleção de dados" (Op. cit., p. 50), mas afirma que Morgan "não conseguiu entender a natureza e a função da terminologia classificatória” que identificou (Op. cit., p. 59). Radcliffe-Brown propóe uma explicação funcional para essa terminologia como alternativa à "história conjectural". O cerne da explicação funcional de Radcliffe- Brown é o conceito de "solidariedade do grupo de germanos". Mas Radcliffe-Brown deixa de mencionar que foi Morgan quem primeiro propôs que os "sistemas classificatórios" poderiam ser explicados por seu papel para a proteção mútua do grupo de germanos. Assim, sua afirmação de que "é óbvio que toda a teoria de Morgan é inteiramente injustificada” ignora a teoria funcional proposta pelo próprio Morgan.

10. Sobre o prolongamento do debate sobre sistemas iroqueses, dravidianos, kariera e crow-omaha, ver ainda Silva (1995, p. 25-28), Barnes ([1984] 2005, p. 194-217), Viveiros de Castro (2002, p. 87-181), Trautmann e Barnes (2008), Trautmann (2008 p. 324-325).

\section{Referências bibliográficas}

ALMEIDA, Mauro W. Barbosa de. Marxismo e Antropologia. In: TOLEDO, Caio N.; BOITO JR., Armando. 
(Orgs.). Marxismo e Ciências Humanas. Campinas: Editora Xamã, CEMARX e FAPESP, p. 48-59, 2003.

BARNES, J. Two Crows Denies It. A History of Controversy in Omaha Sociology. Lincoln e Londres: University of Nebraska Press, [1984] 2005.

CAVAlLI-SFORZA, L. Luca. Genes, Povos e Linguas. São Paulo: Companhia das Letras, 2003.

CAVALLI-SFORZA, Luca; CAVALLI-SFORZA, Francesco. Quem Somos? História da Diversidade Humana. São Paulo: Editora UNESP, 2002.

COHEN G. A. Karl Marx's Theory of History. A Defense. Princeton: Princeton University Press, 1978.

DARWIN, Charles. The Descent of Man. Introdução de James Moore e Adrian Desmond. Londres: Penguin Books, [1871] 2004.

. A Origem das Espécies. São Paulo: Escala, [1859] 2009.

DUMONT, Louis. The Dravidian Kinshp Terminology as an Expression of Marriage. Man, vol. 53, p. 34-39, 1953.

DUMONT, Louis. Dravidien et Kariera. L' Alliance de Mariage dans L' Inde du Sud, et en Australie. Haia e Paris: Mouton, 1975.

ENGELS, Friedrich. Der Ursprung der Familie, des Privateigenthums und des Staats. Stuttgart: Dietz Verlag, 1886.

MARX, Karl; ENGELS, Friedrich. O Manifesto do Partido Comunista. In: Werke. Berlin: Dietz Verlag, vol. 4, p. 459-493, [1890] 1972.

FORTES, Meyer. Kinship and the Social Order: The Legacy of Lewis Henry Morgan. New Bruswick: Aldine Transaction, [1969] 2005.

GODELIER, Maurice; TRAUTMANN, Thomas R.; FAT, F. Tjon Sie. Transformations of Kinship. Washington e Londres: Smithsonian Institution Press, 1998.

GOODENOUGH, Ward H. Yankee Kinship Terminology: A Problem in Componential Analysis. In: TYLER, Stephen A. Cognitive Anthropology. New York: Holt, Rinehart and Winston, p. 255-287, [1865] 1969.

KELLY, Raymond. The Nuer Conquest. The Structure and Development of an Expansionist System. Ann Arbor: The University of MichiganPress, 1985.

KROEBER, Alfred L. 1909. Sistemas Classificatórios de Parentesco. In: LARAIA, Roque de Barros (Org.), Organização Social. Rio de Janeiro, Zahar Editores p. 15-25, [1909] 1969.

KUPER, Adam. The Development of Lewis Morgan's Evolutionism. Journal of the History of the Behavioral Sciences. vol. 21, January, p. 3-22, 1985.

. Reply to Tooker. American Anthropologist. New Series, vol. 95, n.2, p. 443-446, 1993.
LÉVI-STRAUSS. Les Structures Élémentaires de la Parenté. Paris e Haia: Mouton, 1967.

LOUNSBURY, Floyd G. A Formal Account of the Crowand Omaha-Type Kinship Terminologies. In: TYLER, Stephen A. Cognitive Anthropology. New York: Holt, Rinehart and Winston, p. 212-254, [1964] 1969.

LOWIE, Robert H. Relationship Terms. In: BOHANNAN, Paul ; MIDDLETON, John(Orgs.). Kinship and Social Organization. New York: The Natural History Press, p. 39-59, [1929] 1968.

LUBBOCK, John. The Origin of Civilization and Primitive Condition of Man. Londres: Longmans Green, 1870.

MAINE, Henry S. Ancient Law. Its Connection with the Early History of Society, and its Relation to Modern Ideas. Tucson: University of Arizona Press, [1861] 1986.

McLENNAN John F. Primitive Marriage. An Inquiry into the Origin of the Form of Capture in Marriage Ceremonies. Organização e Introdução de Peter Rivière. Chicago e Londres: The University of Chicago Press, [1865] 1970.

MORGAN, Lewis H. Diffusion Against Centralization. A Lecture Delivered Before the Rochester Athenaeum and Mechanic's Association. Rochester Athenaeum: D. M. Dewey, 1852. Fac-simile disponível em: <http:// books.google.com.br>.

- A conjectural Solution of the Origin of the Classificatory System of Relationship. Proceedings of the American Academy of Arts and Sciences, vol. VII, p. 436-467. Cambridge: Welch, Bigelow, and Company, [1868a] 1968. Disponível em: < http://books.google. com.br>.

. The American Beaver and His Works. Philadelphia: J. B. Lippincott \& Co., 1868b.

Systems of Consanguinity and Affinity in the Human Family. Lincoln e Londres: The University of Nebraska Press, [1871] 1997.

Ancient Society. Com prefácio de Elisabeth Tooker. Tucson: The University of Arizona Press, [1877] 1985.

MURDOCK, George P. Social Structure. New York: The MacMillan Company, 1949.

NEEDHAM, Rodney. Rethinking Kinship and Marriage., Londres: Routledge Library Editions, 1971.

OVERING (KAPLAN), Joanna. The Piaroa. A People of the Orinoco Basin. A Study in Kinship and Marriage. Oxford: Clarendon Press, 1975.

RADCLIFFE-BROWN, R. The Study of Kinship Systems. In: _. Structure and Function in Primitive Society, New York, Free Press, 1952.

cadernos de campo, São Paulo, n. 19, p. 309-322, 2010 
322 Mauro William Barbosa de Almeida

Sistemas Africanos de Parentesco e Casamento - Introdução. In:MELATTI, J. C. (Org.). Radcliffe-Brown. Antropologia. São Paulo: Editora Ática, p. 59161, [1950] 1995.

RESEK, Carl. Lewis Henry Morgan. American Scholar. Chicago: The University of Chicago Press, 1960.

RIBEIRO, Darcy. Estudos de Antropologia da Civilização. I. O Processo Civilizatório. Etapas da Evolução Sociocultural. Rio de Janeiro: Civilizaçáo Brasileira, 1972.

RIVERS, W. H. O Método Genealógico de Pesquisa Antropológica. In: OLIVEIRA, Roberto C. de. (Org.). A Antropologia de Rivers. Campinas: Editora da UNICAMP, p. 51-70, [1910] 1991.

SCHENEIDER, David. American Kinship. A Cultural Acount. Chicago: The Universit of Chicago Press, 1980.

. What is Kinship All About? In: REINING Priscilla (Org.). Kinship Studies in the Morgan Centennial Year, Washington: The Anthropological Society of Washington, p. 32-63, 1972.

SILVA, Márcio. Sistemas Dravidianos na Amazonia: O Caso Waimiri-Atroari. In: VIVEIROS DE CASTRO, E. (Org.). Antropologia do Parentesco. Estudos Amerindios. Rio de Janeiro: Editora da UFRJ, p. 25-60, 1995.

STRATHERN, Marilyn. After Nature: English Kinship in the Late Twentieth Century. Cambridge: Cambridge University Press, 1992.

TOOKER, Elisabeth. Introduction. Lewis Morgan, Systems of Consanguinity and Affinity in the Human Family. Lincoln e Londres: The University of Nebraska Press, p. vii-xxi, 1997.

Lewis Morgan and His Contemporaries. American Anthropologist. vol. 94, n. 2, p. 357-375, 1992.

. Reply to Kuper's Commentary. American Anthropologist, vol. 95, n.2, p. 446-448, 1993.

TRAUTMANN, Thomas R.; KABELAC, Karl S. The Library of Lewis Henry Morgan. Philadelphia: Transac- tions of the American Philosophical Society, vol. 84, partes $6-7,1994$.

TRAUTMANN, Thomas R.; BARNES, R. H. "Dravidian", "Iroquois", and "Crow-Omaha" in North American Perspective. In: GODELIER, Godelier; TRAUTMANN Thomas R.;FAT, Franklin E. Tjon Sie.(Orgs.). Transformations of Kinship. Washington: Smithsonian Institution Press, 2008.

TRAUTMANN, Thomas. Dravidian Kinship. Cambridge: Cambridge University Press, 1981.

. Lewis Morgan and the Invention of Kinship.

Berkeley: University of California Press, 1987.

Languages and Nations. The Dravidian Proof in Colonial Madras. Berkeley: University of California Press, 2006.

Lewis Morgan and the Invention of Kinship. New Edition with a new Introduction and Appendices by the Author. Lincoln and London: University of Nebraska Press, 2010.

TYLOR, Edward. Primitive Culture. Cambridge: Cambridge University Press, [1871] 2010.

VIVEIROS DE CASTRO, Eduardo. A Inconstância da Alma Selvagem. São Paulo: Cosac \& Naify, 2002..

WHITE, Leslie A. Lewis H. Morgan's Western Field Trips. American Anhropologist, New Series, vol. 53, n. 1, p. 11-18, 1951.

. How Morgan Came to Write "Systems of Consanguinity and Affinity". Papers of the Michigan Academy of Science, Arts, and Letters, vol. 42, p. 257-268, 1957.

What is a Classificatory Kinshp Term? Southern Journal of Anthropology, vol. 14, n. 4 p. 378-385, 1958.

(org.). Lewis Henry Morgan. The Indian Journals. 1859-1862. Ann Arbor: The University of Michigan Press, 1959.

autor Mauro William Barbosa de Almeida

Professor do Departamento de Antropologia Social / Unicamp

Doutor em Antropologia Social / Universidade de Cambridge

Recebida em 26/10/2010

Aceita para publicação em 26/10/2010

cadernos de campo, São Paulo, n. 19, p. 309-322, 2010 